\title{
Research on the Transformation of Rural Governance Models under the Background of Rural Revitalization
}

\author{
Rongfei Guo \\ School of Finance and Public Administration, Anhui University of Finance and Economics, Bengbu, China \\ Email: RongfeiGuo@163.com
}

How to cite this paper: Guo, R. F. (2020). Research on the Transformation of Rural Governance Models under the Background of Rural Revitalization. Open Journal of Business and Management, 8, 1274-1280. https://doi.org/10.4236/ojbm.2020.83082

Received: April 30, 2020

Accepted: May 25, 2020

Published: May 28, 2020

Copyright (๑) 2020 by author(s) and Scientific Research Publishing Inc. This work is licensed under the Creative Commons Attribution International License (CC BY 4.0).

http://creativecommons.org/licenses/by/4.0/

\section{(c) (i) Open Access}

\begin{abstract}
The strategy of rural revitalization is an important measure to solve the main social contradictions of our country in the new era and achieve the great rejuvenation of the Chinese nation. It embodies the party and the country's great emphasis on rural development and has extremely far-reaching significance. However, the traditional rural governance model has a series of problems, such as low level of farmers' participation, ambiguous government function positioning, imperfect governance system, and serious administration of grassroots organizations. It is incompatible with the requirements of rural construction in the new era, resulting in slow rural development and further urban-rural gap enlarge. Therefore, it is necessary to stimulate farmers' enthusiasm for participation, improve the governance environment, and promote measures by strengthening participatory governance led by party building, clearing function positioning, improving system policies, and reducing the administrative burden of grassroots organizations. Promote the transformation of the rural governance model and realize the rural revitalization at an early date.
\end{abstract}

\section{Keywords}

Rural Revitalization, Rural Governance, Path Direction

\section{Introduction}

As one of the main spaces of human life, the countryside has multiple functions of production, life, and ecology. It has a crucial decisive role in the rise and fall of the country. Rural growth means national prosperity, and rural decline means national decline. Therefore, in the report of the 19th National Congress of the 
Communist Party of China, the strategy of rural revitalization was put forward, insisting on the priority of agricultural and rural development, strengthening rural grassroots work, attaching great importance to the solution of the issues relating to agriculture, rural areas and rural people, and constantly advancing the modernization of rural areas to achieve comprehensive changes in rural society.

Rural governance is an important part of the national governance system, and also a key link in the comprehensive realization of the rural revitalization strategy. With the progress of the times and the development of economy and society, rural governance has undergone changes from the integration of government and society, township governance and village governance to the construction of new rural areas, and the current stage of targeted poverty alleviation in rural revitalization (Li, 2019). Whether rural governance is effective directly affects the long-term development of rural grassroots society and the quality of life of the working people, and is closely related to the modernization of national governance and social harmony and stability. Therefore, how to carry out rural governance transformation according to the current situation of rural development and policy requirements is of positive significance and important value to promote the modernization of the rural governance system and implement the strategy of rural revitalization.

\section{Dilemma}

\subsection{Low Level of Farmers' Participation}

In the current rural governance, the main problem is the low level of participation of farmers. First, due to the development of the market economy and the acceleration of the urbanization process, many young people in rural areas have gone out to work, and a large amount of labor has flowed out. This situation prevents some knowledgeable and capable people from participating in governance. Second, affected by traditional thinking, villagers generally lack the awareness of independent participation and democratic consultation (Wei, 2018), and the current rural governance transformation process is mainly based on policy calls, lacking spiritual and material incentives, and there is no obvious difference between farmers participating and not participating. Therefore, it is difficult to mobilize their enthusiasm to participate. Third, there is authoritarian governance and contracted governance. These two governance models have the characteristics of being administratively dominated, mainly because some grassroots workers have a weak sense of democracy. Administrative staff usually use their own power to conduct governance alone in order to complete tasks as quickly as possible, without seriously listening to villagers' opinions (Zhou, 2016). Although this type of governance has achieved certain results, the lack of farmers' participation is not conducive to the overall development of rural governance. 


\subsection{Ambiguous Government Function Positioning}

As the middle level of the administrative system, the main functions of the township government are generally to implement the policies of the higher level, guide the governance of rural grassroots organizations, and promote the continuous development of the rural economy and society. However, in reality, the township government has deviated in its functional positioning. In the process of ordering, only the superior policies were directly communicated to the grassroots cadres, lacking the necessary guidance and assistance for rural governance affairs, lack of timely and effective communication, and breaking away from the grassroots masses, leading grassroots organizations to undertake some tasks that originally belonged to the government. There is no effective division of labor between the two, and there are problems in the allocation of power, which reduces governance efficiency and brings difficulties to the transformation of the rural governance model (Han, 2020).

\subsection{Imperfect Governance System}

With the continuous development of the economy and society, the rural production, lifestyle and population structure have changed accordingly, but there are still some governance systems that have not been reformed and improved in time with the changes in the times, and the system has not been fully established. The imperfection of the rural governance system has led to some irregular governance systems, relatively lagging governance models, unscientific governance structures, lack of supervision mechanisms and democratic participation in the governance process, lack of necessary feedback mechanisms and counseling and discussion platforms, and poor channels for villagers to express opinions, lack of relevant institutional guarantees and other institutional bottlenecks in the optimization and development of the rural economic structure (Yan, 2020). It can be seen that the imperfect governance system restricts the transformation and development of the rural governance model. It is necessary to establish and improve the corresponding governance system and form a complete rural governance system as soon as possible, which will play a positive role in promoting the modernization of rural governance and early achieving rural revitalization.

\subsection{Serious Administration of Grassroots Organizations}

Due to the current lack of rural autonomy, in order to better promote the relevant systems of national governance, it is still necessary for local governments to give grassroots organizations certain administrative powers to enable them to better provide public services and implement various policies. However, under the actual current pressure system, the administrative affairs and pressure of grassroots organizations are very heavy. The so-called pressure system refers to an administrative system in which the superior sets goals and tasks, decomposes county, township, and village level by level to reward and punish the completion of tasks. The tasks formulated by the central government are distributed layer by 
layer in cities, counties, towns, and rural areas. Then, the superiors conduct inspections, evaluations, and acceptances. Rewards are given to organizations and individuals who have accomplished outstanding work tasks. Criticism and punishment will be given to those who fail to complete or fail to meet the quality standards. Under this pressure system, village cadres have no effective grasp of farmers, which has formed a "monorail politics", allocating tasks from top to bottom, and in this layer of distribution, undoubtedly increased to grassroots cadres work tasks and pressure. A large number of administrative affairs have led to the serious administration of grassroots organizations. Grassroots personnel are too busy with administrative work to take care of various tasks of rural governance (Zhang \& Zhang, 2018).

\section{Solution Path}

\subsection{Strengthen Participatory Governance Led by Party Building}

Farmers are the main body of rural governance. The government should change its role, empower and empower farmers, strengthen participatory governance led by party building, and combine dual-track governance, administrative governance and social governance, hard governance and flexible governance to stimulate the enthusiasm of the villagers to participate and improve the participation of the villagers. First, party organizations should actively transform their functions and strengthen functional party building. Functional party building refers to breaking the geographical and political boundaries and forming different party organizations according to the interests and hobbies of party members to better carry out special work. In this way, not only party members can be organized, but also those who are willing to join the party can be organized to bring the party and the mass together, and the party and social organizations together, which is conducive to enhancing social cohesion, inspiring the enthusiasm of the masses, and promoting farmers' participation. Second, use democratic consultation mechanisms. Through the negotiation of multiple parties (such as village cadres and villagers preliminary consultation, and then village cadres and town cadres to negotiate again) to formulate the project work implementation plan and final goals, to ensure that farmers can fully express their opinions and suggestions through smooth channels, truly participating in community governance. Third, change the governance line. Transform the logic of the cadre line into the logic of the mass line, that is, transform the previous slogan-style mass participation and the actual cadre participation into real mass participation under the leadership of the party organization, apply good participatory governance, adhere the line from the masses to the masses. Fourth, raise the awareness of villagers' participation. Through carrying out various governance activities, a governance culture with regional characteristics is formed, the overall cohesion of the countryside is improved, the rural public culture is cultivated, villagers are encouraged to participate actively, and farmers' sense of identity is enhanced (Wang, Li, \& Du, 2020). Fifth, let farmers get actual benefits 
in the process of participation. Carry out corresponding skill training according to the actual conditions of farmers' interests, hobbies, etc., improve their professional skills and competitiveness, encourage their employment and entrepreneurship, and increase income of them. Take improving the economic life of farmers as an important goal of rural governance, let farmers change their minds, and turn passive participation into active participation (Wen, 2020). It should be noted that participatory governance does not mean that the government will not play a role at all, but that the government supports mass participation, rewards groups that actively participate and has significant results, and punishes those who undermine governance results.

\subsection{Clear Function Positioning}

First of all, it is necessary to clarify the functional positioning of the county and village at all levels. All functional departments clarify their roles and responsibilities, corresponding powers and responsibilities, clear division of labor, to avoid the phenomenon of cross-functional positions and mutual responsibility blame. Secondly, establish a "multiple governance" rural governance pattern. County and township governments, rural grassroots organizations, and rural residents should actively participate in rural governance, play their due role in them, take their responsibilities and perform their respective duties, realize joint governance of multiple subjects, and improve the effectiveness of rural governance (Han, 2020). Finally, strengthen communication between the government and the grassroots. The government, grassroots organizations and farmers should communicate in a timely manner to achieve information sharing. The government needs to listen carefully to the feedback and governance suggestions from the grassroots, expand communication channels, establish and improve online and offline service platforms, and make the process of rural governance oriented masses, serve the masses.

\subsection{Improve System Policies}

The grass-roots government should adjust and improve the corresponding system policies according to the current changes in rural governance and the level of governance to provide policy planning and system guarantees for the implementation of various rural governance tasks. First, establish and improve the leadership decision-making mechanism. The main body of decision-making should fully consider various factors that affect decision-making before making a decision, formulate reasonable and effective decision-making rules, strengthen the construction of a clean government, and ensure that the decision-making process is transparent, democratic and scientific. Second, improve democratic participation and supervision mechanisms. Promote the development of democratic elections and supervision systems, encourage villagers to participate in decision-making, deliberations and other related matters, guarantee farmers' legal rights to participate in governance, and form a new situation of pluralistic go- 
vernance (Wei, 2018). Third, introduce a talent introduction mechanism and social capital incentive policies. On the one hand, effective rural governance requires professional talents. It can make up for some problems in the current rural governance in terms of personnel structure and management methods through the professional governance and public services they provide. Therefore, it is necessary to formulate a professional talent introduction mechanism and adopt certain incentive policies to attract professional talents from multiple channels. Then conduct training in combination with the actual governance situation of the village, making it an important support for rural governance and injecting fresh blood into rural governance. On the other hand, financial support is also a major condition for the transformation of the rural governance model when human resources are met. Introduce preferential incentive policies to introduce social capital, encourage entrepreneurs and investors to participate in projects such as rural agriculture, ecotourism, resource development and new-type industrial development, drive the reform of rural industrial economic structure. At the same time, establish a long-term supervision and review mechanism to ensure enterprises conduct standardized operation and management, thereby promoting the vigorous development of the rural economy.

\subsection{Reduce the Administrative Burden of Grassroots Organizations}

First, simplify administrative processes and focus on substance rather than form. Release local governments and grassroots organizations from a pressure-based system, simplify grassroots administrative tasks and procedures. Don't require the grassroots to repeatedly fill out forms and report materials, reduce formal work flowing on the surface, reform the inspection and assessment methods, and attach importance to judging the quality of work with actual results. No red tape, no fancy tricks (Zhao, Ma, \& Liu, 2019). Second, give grassroots organizations more autonomy. As the main participants in rural governance and the main promoter of rural revitalization strategies, grassroots organizations play many functions such as communication, leadership, planning, and governance. Therefore, the government should give it some autonomy to better lead mass participation in rural governance. Third, participate actively. Grassroots organizations should actively participate in rural governance, implement various governance work in place, insist on in-depth field investigations, maintain close contact with the grassroots, find problems from the actual situation, solve problems, and thus promote the progress and improvement of the entire governance process.

\section{Conclusion}

All in all, rural development is a process, and the transformation of the rural governance model also requires gradual progress. Under the background of implementing the rural revitalization strategy, carrying out research on the transformation of the rural governance model is conducive to solving various prob- 
lems in the process of rural governance, promoting the development of the rural economy and improving the living standards of farmers, thus continuously strengthening the rural governance system and governance capacity building, forming a new model of rural governance, to achieve the prosperity of rural society.

\section{Conflicts of Interest}

The author declares no conflicts of interest regarding the publication of this paper.

\section{References}

Han, M. J. (2020). Practical Dilemma and Outlet of Rural Governance Transformation under Rural Revitalization Strategy. Modern Management Science, No. 1, 59-61.

Li, X. S. (2019). The Model Change and Evolution Logic of Rural Governance in China-Based on the Perspective of the Relationship between the State and Society. Journal of Yunnan Normal University (Philosophy and Social Sciences Edition), 51, 94-102.

Wang, Q., Li, T. Y., \& Du, Y. (2020). Excellent Governance Plan for the Modernization of China's Rural Governance in the New Era. Journal of University of Electronic Science and Technology of China (Social Science Edition), 7, 1-7.

Wei, S. S. (2018). Difficulties and Transformation of Rural Governance under the Background of Rural Revitalization. People's Forum, No. 2, 64-65.

Wen, F. G. (2020). Development and Enlightenment of Rural Community Governance in China: Based on the Perspective of Rural Revitalization Strategy. Journal of Hubei University (Philosophy and Social Sciences Edition), 47, 148-156+168.

Yan, J. (2020). Research on the Path of Rural Governance Modernization from the Perspective of Rural Revitalization. The House of Drama, No. 8, 199-200.

Zhang, X. W., \& Zhang, G. L. (2018). Transformation of Major Social Contradictions, Transformation of Rural Governance and Rural Revitalization. Journal of Northwest A\&F University (Social Science Edition), 18, 63-71.

Zhao, S. F., Ma, T. T., \& Liu, P. J. (2019). "Integrating the Three Communities": Research on the Practice and Optimization Countermeasures of Xiaogang Village Community Governance Innovation Action. Journal of Xichang College (Social Science Edition), $31,36-42$.

Zhou, Q. Z. (2016). On Chinese Community Governance-Transition from Authoritarian Governance to Participatory Governance. Learning and Exploration, No. 6, 38-47+159. 